\title{
A Correct Approach to the "Picture" of a Patient with Cardiovascular Disease
}

\section{Editorial}

Although the control of heart disease undoubtedly shows promising results, the morbidity and mortality from cardiovascular events is characterized by a high rate [1-3], and such a fact should be carefully taken into account.

Ischemic heart disease, complicated hypertension and, generally, cerebrovascular events, mainly associated with stroke, involve the engagement of physicians and health staff to fight these occurrences primarily by therapeutic approaches, changes in lifestyle and reduction of the major cardiovascular risk factor effects [4-6]. The last of these three factors should be investigated as a matter not fully understood in terms of numbers, continuously in progress, and real role in causing cardiovascular disease. Therefore, their exact classification needs to be further studied.

Among cardiovascular diseases, ischemic heart disease is worthy of mention since it occurs with high rate with regard to both morbidity and mortality. In addition, many subjects, also under 70 years, sometimes meet loss of working and severe disability as a result of this outcome. The "picture" of an individual suffering from ischemic heart disease consists mainly of clinical signs due to reduced blood flow supply to the myocardium because of coronary artery alterations and hypoxia [7-9]. A typical chest pain, although with different features, duration, and response to administered nitroglycerin, is the relevant symptom of these individuals, who can also display heart failure and arrhythmias. A suitable therapeutic approach associated with changes in lifestyle and careful control of the major cardiovascular risk factors may reduce the rate of the disease as well as improving its outcome. This way should be certainly followed since ischemic patients pay high costs in terms of life and social engagement.

Hypertension is a disease often recognized occasionally during a routine outpatient examination. Therefore, its real rate is far to be completely assessed [10]. The "picture" of a hypertensive patient is silent in a large majority of patients. However, in presence of diagnosis of the disease, a valid therapeutic approach has to be conducted to reduce the rate of complications mainly characterized by severe organ damage. Heart, brain and kidney are primarily affected when high values in blood pressure exist. The main purpose of antihypertensive therapy and changes in lifestyle is to achieve the most significant lowering of blood pressure, anyway obtained $[11,12]$. However, poor adherence to antihypertensive therapy still may be observed [13] as a result of discontinuous compliance of patients and, also, lack of attention to the treatment by family physicians. If this behavior is overtaken, a more definite "picture" of the hypertensive individual could be observed, characterized by an evident improvement of patient health and reduction of hypertensive complications.

\author{
Editorial \\ Volume 5 Issue 1 - 2016 \\ Aurelio Leone* \\ ${ }^{1}$ Fellow of the American Society of Hypertension (FASH), USA \\ ${ }^{2}$ Fellow of the Royal Society for Promotion of Health (FRSPH), \\ $U K$ \\ ${ }^{3}$ Editor-in-Chief of the Journal of Cardiology \& Current \\ Research, USA \\ *Corresponding author: Aurelio Leone, Fellow of the \\ American Society of Hypertension (USA), Fellow of the \\ Royal Society for Promotion of Health (UK), Editor-in-Chief \\ of the Journal of Cardiology \& Current Research (USA), \\ Via Provinciale 27, 19030 Castelnuovo Magra, Italy, Email: \\ reliol@libero.it \\ Received: January 14, 2016 | Published: : January 27, 2016
}

Cerebrovascular disease consists of a group of disorders of the brain circulation mainly due to a reduction or absence of blood flow supply. The most severe pattern to be observed is the stroke in both its forms: thrombotic and hemorrhagic stroke $[14,15]$. The patient affected by stroke shows a typical "picture" depending on clinical signs and pathologic lesions. Several symptoms may accompany this vascular disorder. Among these, sudden loss of balance often followed by vomiting, severe headache and, also, loss of consciousness may be seen. When an individual survives a stroke, permanent disability of different degree often characterizes the future of this subject.

An ischemic stroke shows about $70 \%$ of the rate of all types of stroke and is mainly a consequence of atherosclerotic vascular disorders. Carotid and cerebral artery alterations of thrombotic type are the pathological substrate more frequently responsible of the damage. In addition, atrial fibrillation plays a significant role. On the contrary, hemorrhagic infarction, which occurs for about $15 \%$ of all strokes, primarily results from intracerebral hemorrhage due to rupture of cerebral arteries often affected by a congenital aneurysm. In terms of "picture" of the cerebrovascular disease, stroke is the event that easily may be identified since it modifies physical features of the subjects affected in a very significant manner.

\section{Conclusion}

From these observations, it emerges that the "picture" of a patient suffering from cardiovascular disease should not be interpreted as a static, but dynamic "picture", whose characteristics may be modified or, otherwise, controlled by using a correct approach built up several measures to better fight the underlying 
pathology. It is superfluous emphasizing each cardiovascular disorder has an own feature depending on several and variable factors to be taken into account when the manifestations of a single disease have to be assessed. Finally, improving the "picture" of a cardiopathic individual contributes significantly to reduce health costs, which are still high for the cardiovascular disease control.

\section{References}

1. Lerner DJ, Kannel WB (1986) Patterns of coronary heart disease morbidity and mortality in the sexes: a 26-year follow-up of the Framingham population. Am Heart J 111 (2): 383-390.

2. Barrett-Connor E (1997) Sex differences in coronary heart disease Why are women so superior? The 1995 Ancel Key Lecture. Circulation 95(1): 252-264.

3. Dahlof B, Devereux RB, Kjeldsen SE, Julius S, Beevers G, et al. (2002) Cardiovascular morbidity and mortality in the Losartan Intervention For Endpoint reduction in hypertension study (LIFE): a randomized trial against atenolol. Lancet 359 (9311): 995-1003.

4. Leone A (2005) Biochemical markers of cardiovascular damage from tobacco smoke. Curr Pharm Des 11(17): 2199-2208.

5. Kannel WB, Gordon T (1978) Evaluation of cardiovascular risk in the elderly: The Framingham Study. Bull NY Acad Med 54(6): 573-591.

6. Leone A (2015) How does to quit smoking influence the effects of other major cardiovascular risk factors? J Cardiol Curr Res 3(6): 00125 .
7. Davies SW (2001) Clinical presentation and diagnosis of coronary artery disease: stable angina. Br Med Bull 59: 17-27.

8. Irwin S (1985) Clinical manifestations and assessment of ischemic heart disease. Phys Ther 65(12): 1806-1811.

9. Leone A (2003) Relationship between cigarette smoking and other coronary risk factors in atherosclerosis: risk of cardiovascular disease and preventive measures. Curr Pharm Des 9(29): 2417-2423.

10. Kearney PM, Whelton M, Reynolds K, Whelton PK, He J (2004) Worldwide prevalence of hypertension: a systematic review. J Hypertens 22(1): 11-19.

11. Leone A (2015) The control of blood pressure worldwide: A glimmer of success. J Cardiol Curr Res 3(5): 00117.

12. Mancia G, Fagard R, Narkiewicz K, Redòn J, Zanchetti A, et al (2013) 2013 ESH/ESC Guidelines for the management of arterial hypertension. J Hypertens 31(7): 1281-1357.

13. Salvetti A, Versari D (2003) Control of blood pressure in the Community: An unsolved problem. Curr Pharm Des 9(29): 23752384 .

14. Brown RD, Whisnant JP, Sicks JD, O'Fallon WM, Wiebers DO (1996) Stroke incidence, prevalence, and survival: secular trends in Rochester, Minnesota, through 1989. Stroke 27(3): 373-380.

15. Barnett HJ, Gunton RW, Eliasziw M, Fleming L, Sharpe B, et al. (2000) Causes and severity of ischemic stroke in patients with internal carotid artery stenosis. JAMA 283(11): 1429-1436. 